10-ARTIGO ORIGINAL

\title{
Caracterização de um modelo experimental de Diabetes Mellitus, induzido pela aloxana em ratos. Estudo clínico e laboratorial ${ }^{1}$
}

\author{
Mauro Masson Lerco ${ }^{2}$ \\ César Tadeu Spadella ${ }^{3}$ \\ José Lúcio Martins Machado ${ }^{4}$ \\ Silvana Artioli Schellini ${ }^{5}$ \\ Carlos Roberto Padovani ${ }^{6}$
}

\begin{abstract}
Lerco MM, Spadella CT, Machado JLM, Schellini SA, Padovani CR. Caracterização de um modelo experimental de Diabetes mellitus, induzido pela aloxana em ratos. Estudo clínico e laboratorial. Acta Cir Bras [serial online] 2003 Mar-Abr;18(2). Disponível em URL: http://www.scielo.br/acb.

RESUMO - Objetivo: O presente estudo teve por objetivo caracterizar as alterações clínicas e laboratoriais do rato portador de Diabetes Mellitus induzido pela administração endovenosa de aloxana. Métodos: Os animais foram distribuídos, por sorteio, em dois grupos experimentais: Grupo Controle Normal (G1), constituído de 25 animais sadios, e Grupo Diabético (G2), formado por 25 animais diabéticos graves, que foram avaliados em cinco momentos (1, 3, 6, 9 e 12 meses) de seguimento, tendo sido estudados os seguintes parâmetros: evolução clínica (peso, ingestão hídrica, ingestão alimentar e diurese) e exames bioquímicos (glicemia de jejum, glicose urinária, glicosúria, cetonúria, colesterol total, colesterol HDL, triglicérides e lipídios). Resultados: A injeção de aloxana $2 \%$ na via endovenosa do rato acompanhou-se de um índice de mortalidade de $39 \%$, tendo produzido diabetes grave também em 39\% dos animais. O diabetes foi caracterizado por queda progressiva do peso corporal, elevação substancial da ingestão hídrica, ingestão alimentar e da diurese, com valores glicêmicos acima de $300 \mathrm{mg} / \mathrm{dl}$, glicosúria $3+\mathrm{e}$, eventualmente, cetonúria. O diabetes não altera o perfil de colesterol e lípides de ratos a longo prazo. Conclusão: Nossos estudos revelam que a aloxana produz, no rato, alterações clínicas e laboratoriais características de diabetes grave, as quais possibilitam estudos a longo prazo do diabetes.
\end{abstract}

DESCRITORES - Diabetes. Aloxana. Ratos.

\section{Introdução}

O Diabetes Mellitus é um problema de saúde pública mundial. Estima-se que existam mais de 150 milhões de pessoas com diabetes no mundo, sendo que projeções da Organização Mundial de Saúde para 2025 sugerem que esse número possa chegar a 300 milhões.

Em 2000, os seis países com o maior número de pacientes diabéticos eram: Índia (32,7 milhões), China

1. Trabalho realizado no Laboratório de Técnica Cirúrgica e Cirurgia Experimental da Faculdade de Medicina de Botucatu - UNESP; parte integrante da Dissertação de Mestrado apresentada à FMB - UNESP; pesquisa laureada com o prêmio "Miguel Couto" da Academia Nacional de Medicina no ano de 2001.

2. Professor Assistente do Departamento de Cirurgia e Ortopedia da Faculdade de Medicina de Botucatu da UNESP.

3. Professor Adjunto do Departamento de Cirurgia e Ortopedia da Faculdade de Medicina de Botucatu da UNESP

4. Professor Doutor do Departamento de Cirurgia e Ortopedia da Faculdade de Medicina de Botucatu da UNESP.

5. Professora Adjunta do Departamento de Oftalmologia da Faculdade de Medicina de Botucatu da UNESP.

6. Professor Titular do Departamento de Bioestatística do Instituto de Biociências do Campus da UNESP de Botucatu. 
(22,6 milhões), Estados Unidos (15,3 milhões), Brasil (12 milhões), Paquistão (8,8 milhões) e Japão (7,1 milhões) (OMS 2001). No Brasil, aproximadamente $50 \%$ das pessoas com diabetes desconhecem sua condição mórbida sendo que $10 \%$ delas são portadoras de diabetes do tipo I (Franco e col. $\left.{ }^{1}\right)$. Em alguns países esse percentual sobe para 80\% (OMS 2001).

Embora se reconheçam os avanços conseguidos, lamentavelmente o diabetes ainda é, hoje, uma das principais causas de incapacitação física para o trabalho, tornando o seu portador 25 vezes mais propenso à cegueira, 17 vezes mais susceptível à nefropatia, com chances cinco vezes maiores de uma amputação de membros e o dobro de risco de uma doença cardiovascular (La Porte ${ }^{2}$; Królewski e col. ${ }^{3}$ ).

O diabetes está associado ao aumento da aterosclerose, observada em autópsias de infarto agudo do miocárdio, elevando as chances de desenvolver trombose e infarto cerebral, bem como gangrena de membros inferiores, numa incidência duas vezes maior que a população não-diabética. Embora a aterosclerose isolada seja um importante fator de risco para essas afecções, freqüentemente ela é complicada pela presença da microangiopatia diabética disseminada $\left(\mathrm{Kuller}^{4}\right)$.

Frente a essa dura realidade, torna-se imprescindível a melhor compreensão dos mecanismos fisiopatológicos do diabetes e de suas complicações, à procura de um tratamento capaz de contribuir às alterações endócrino-metabólicas causadas pela doença e, principalmente, as lesões crônicas sobre os diferentes órgãos.

Neste particular, os estudos experimentais sobre o diabetes têm sido extremamente necessários. Justifica-se, portanto, a sedimentação dos conhecimentos sobre os vários modelos-animais existentes, como o apresentado neste artigo, com o uso da aloxana.

\section{Métodos}

Foram utilizados, no presente trabalho, 89 ratos alogênicos (Rattus norvegicus, variedade albinus) de ambos os sexos, adultos, sadios ao exame clínico, pesando entre 200 e $300 \mathrm{~g}$, com aproximadamente três meses de idade, fornecidos pelo Biotério Central do Campus de Botucatu - UNESP. Após um período de adaptação de sete dias, 25 animais foram sorteados para compor o Grupo Controle Normal (G1). Os 64 animais restantes foram submetidos à injeção endovenosa de aloxana (5,6 Dioxiuracil monohidrato) diluída em solução aquosa a $2 \%$, na dose única de $42 \mathrm{mg} / \mathrm{kg}$ de peso corporal. Desses, 25 animais com diabetes experimental grave foram alocados no Grupo Diabético (G2), sendo os demais desprezados por não terem ficado diabéticos, terem desenvolvido diabetes leve ou morrido após a utilização da droga.

\section{Grupos experimentais}

Como descrito, os animais da presente investigação foram distribuídos em dois grupos experimentais: Grupo Controle Normal (G1): constituído de 25 ratos sadios, não-diabéticos; Grupo Diabético (G2): constituído de 25 ratos diabéticos graves, sem qualquer tipo de tratamento.

Com base na data da avaliação, os animais de ambos os grupos experimentais foram subdivididos, por sorteio, em cinco subgrupos, compostos por cinco animais normais e cinco animais diabéticos cada um e alocados para seguimento e avaliação após 1, 3, 6, 9 e 12 meses.

\section{Parâmetros estudados}

Foram estudados os seguintes atributos: clínicos, aspecto geral, peso, ingestão hídrica, ingestão alimentar, diurese) e laboratoriais: exames bioquímicos (glicemia de jejum, glicose urinária, glicosúria, colesterol total e fração HDL, triglicérides e lipídios).

\section{Momentos de avaliação}

Os 25 animais normais e os 25 animais diabéticos foram avaliados, respectivamente, em cinco momentos, com 1, 3, 6, 9 e 12 meses de seguimento ou diabetes.

\section{Técnicas utilizadas}

\section{Indução do diabetes experimental}

O diabetes experimental foi induzido pela administração de uma solução aquosa de aloxana a $2 \%$ (Aloxan-Sigma - St. Louis - USA), injetada por via endovenosa, na dose única de $42 \mathrm{mg} / \mathrm{kg}$ de peso corporal, utilizando uma das veias da cauda do animal.

Após jejum alimentar de 12 horas, com fornecimento de água "ad libitum", cada rato foi colocado em uma caixa aquecida com lâmpada elétrica, durante um período de aproximadamente 10 minutos; tempo necessário para uma boa visualização das veias da cauda. Após esse procedimento, o animal foi contido em uma pequena caixa individual, tendo sua cauda exposta, após o que se procedeu à inoculação da droga, utilizando-se agulhas de calibre $13 \times 4,5 \mathrm{~mm}$. Decorridos 30 minutos 
do tratamento, os animais foram alimentados normalmente.

Foram utilizados apenas, os animais que apresentaram perda de peso, aumentos relevantes da ingestão hídrica e do débito urinário, acompanhados de alterações laboratoriais, compatíveis com diabetes grave, em duas determinações sucessivas (7 e 14 dias após a indução), representadas por glicemia de jejum acima de $200 \mathrm{mg} / \mathrm{dl}$, glicose urinária maior ou igual a 3000 $\mathrm{mg} / \mathrm{dl}$ e glicosúria positiva $(+++)$ no teste de fitas reagentes Uriscan Gluketo (Pharmaceutical Corp. YEONGDONG - Seoul Korëa).

Os animais cujos valores glicêmicos foram menores que $120 \mathrm{mg} / \mathrm{dl}$, ou que apresentaram glicemias intermediárias entre 120 e $200 \mathrm{mg} / \mathrm{dl}$, com ou sem sinais clínicos de diabetes, foram desprezados.

\section{Avaliação clínica e laboratorial}

Os dados clínicos de ambos os grupos experimentais, incluindo peso, ingestão hídrica, ingestão alimentar e diurese, bem como os dados laboratoriais referentes às dosagens de glicose plasmática, glicose urinária e glicosúria de todos os animais foram realizados, inicialmente, com 14 dias de seguimento no Grupo Controle Normal e no $14^{\circ}$ dia após a indução do diabetes no Grupo Diabético. Posteriormente, as avaliações foram feitas após o $1^{\circ}, 3^{\circ}, 6^{\circ}, 9^{\circ}$ e $12^{\circ}$ mês de seguimento.

No sacrifício, além dos exames laboratoriais colhidos no seguimento, foi coletado sangue para dosagens de colesterol total e fração HDL, lípides totais e triglicérides.

\section{Metodização empregada na coleta de dados}

Para a coleta dos dados clínicos e laboratoriais, cada animal foi submetido a um esquema padronizado de avaliação. A metodologia foi a seguinte: a) colocação dos animais em gaiolas metabólicas individuais durante 24 horas;

b) fornecimento de volume conhecido de água durante todo o período de 24 horas (Figura 1-A);

c) fornecimento de quantidades conhecidas de ração Nuvilab-CR1 (NUVITAL Nutrientes Produtos Veterinários Ltda. - Curitiba - PR) durante o período noturno de 12 horas, após o que se retirou toda a alimentação, por um período diurno de 12 horas (jejum de 12 horas);

d) determinação, no final do procedimento, do peso do animal em gramas, do volume de água ingerido em 24 horas (ingestão hídrica de $24 \mathrm{~h}$ em mililitros), da quantidade de alimento consumido em 12 horas (ingestão alimentar de $12 \mathrm{~h}$ em gramas) e do volume de diurese de 24 horas (diurese de $24 \mathrm{~h}$ em mililitros);

e) coleta de amostra de $10 \mathrm{ml}$ de urina coletada em 24 horas, para a dosagem de glicose urinária, em miligramas por decilitro, após jejum de 12 horas, seguida da realização de glicosúria e cetonúria através de fitas reagentes;

f) coleta de uma amostra de $1,5 \mathrm{ml}$ de sangue para a dosagem da glicose plasmática, em miligramas por decilitro, após um jejum de 12 horas.

Para a realização deste item, os animais foram colocados em uma caixa aquecida com lâmpada incandescente, a uma temperatura de $39-45^{\circ} \mathrm{C}$, por um período de 10 minutos. A seguir, os ratos foram sangrados por secção da cauda, com retirada do volume de sangue necessário para os exames bioquímicos. Posterior a esse procedimento, a cauda secionada foi amarrada, com finalidade hemostática, com fio de algodão 2-0 (Figura 1-A,B,C e D). Os animais foram, então, acomodados em caixas individuais, recebendo água e ração "ad libitum". No momento do sacrifício, o sangue foi coletado por punção cardíaca a céu aberto. 

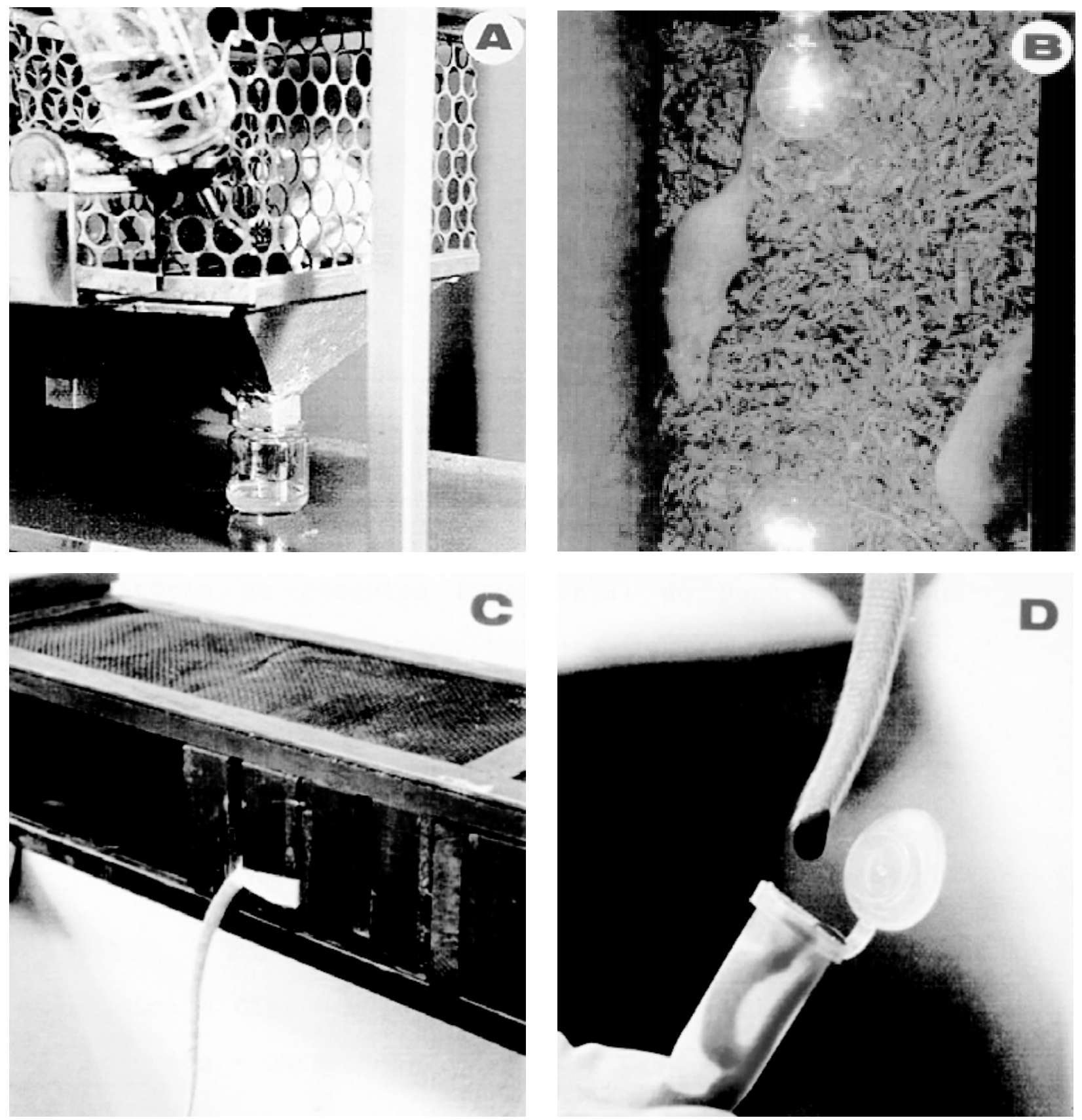

FIGURA 1 - Avaliação de parâmetros clínicos e laboratoriais: A:- animal sob controle clínico em gaiola metabólica; B:- ratos em caixas aquecidas para obtenção de sangue; C:- imobilização da cauda do animal; D:- secção da cauda e coleta de sangue.

\section{Exames laboratoriais}

As dosagens de glicose plasmática e urinária foram realizadas no Laboratório de Pesquisa Experimental do Departamento de Pediatria da Faculdade de Botucatu UNESP, empregando-se o método por dosagem enzimática ( Glicose -E ) - CELM Cia Equipadora de Laboratórios Modernos - Barueri. As pesquisas de glicosúria e cetonúria foram feitas empregando-se fitas reagentes (Uriscan Gluketo).
As dosagens de colesterol total, fração HDL e lipídios totais foram realizadas no Laboratório Clínico da Faculdade de Medicina de Botucatu - UNESP, por método enzimático colorimétrico (SERA-PAK Cholesterol fast color e SERA-PAK - Triglycerides fast color) - Bayer Corporation, Diagnostics Division Tarrytown - NY - USA e Laboratórios de Análises Clínicas da FMB - UNESP - Botucatu - SP.

As dosagens de lípides totais foram realizadas no Laboratório Clínico da Faculdade de Medicina de 
Botucatu - UNESP, pelo método de Cantarow-Trumper (1962) com leitura por espectrofotometria.

\section{Métodos estatísticos}

O estudo das variáveis clínicas (peso, ingestão hídrica, ingestão alimentar e diurese) e laboratoriais (glicemia, glicose urinária, colesterol total, colesterol HDL, triglicérides e lipídio total), segundo os grupos controle e diabético e momentos de sacrifício, foi realizado através da técnica de análise de variância para o esquema fatorial $2 \times 5$ (dois grupos em cinco momentos), no delineamento inteiramente casualizado, complementado com o teste de comparações múltiplas de Tukey (Montgomery ${ }^{5}$ ).

Todas as discussões estatísticas foram realizadas no nível de 5\% de significância.

\section{Resultados}

\section{Quanto ao método de indução do diabetes}

A injeção endovenosa de aloxana numa das veias da cauda do rato foi realizada com bastante facilidade, uma vez que, antes da injeção, o animal foi colocado durante 10 minutos no interior de uma caixa aquecida com lâmpada elétrica, o que proporcionou um grau de vasodilatação evidente.

Dos 64 animais submetidos à injeção endovenosa de aloxana, diluída em solução aquosa a $2 \%$, na dose de $42 \mathrm{mg} / \mathrm{kg}$ de peso corporal, 14 ratos $(21,8 \%)$ não ficaram diabéticos ou desenvolveram a doença numa gravidade leve ou moderada, sendo desprezados. Dos $78 \%$ restantes, 25 animais (39\%) morreram durante a $1^{2}$ semana após a indução, sendo que 25 animais desenvolveram diabetes experimental grave tendo sido colocados em seguimento nos respectivos subgrupos.

\section{Evolução clínica}

Os 25 animais do Grupo Controle Normal (G1) evoluíram sem quaisquer alterações clínicas durante todo experimento, sendo avaliados nos cinco momentos estabelecidos $\left(1^{\circ}, 3^{\circ}, 6^{\circ}, 9^{\circ}\right.$ e $12^{\circ}$ mês de seguimento) em bom estado geral (Figuras 2B e 3B). Os parâmetros clínicos representados pela evolução do peso, ingestão hídrica, ingestão alimentar e diurese mantiveram-se dentro dos níveis médios esperados para ratos sadios de mesma idade. Os valores encontrados estão representados nas Figuras 4 e 5. Os 25 animais que compuseram o grupo diabético (G2) evoluíram com parâmetros clínicos e laboratoriais compatíveis com diabetes grave. Esses animais apresentaram, ao longo do seguimento, progressiva queda do estado geral, perda inicial de peso após a indução e ganho significativamente menor de peso em relação ao rato normal, com declínio progressivo da curva ponderal próximo ao óbito (Figura 2A). Também observamos alteração da pelagem, aumento da circunferência abdominal, devido ao intestino grosso distendido e palpável, além de catarata bilateral (Figura 3A) e episódios freqüentes de pediculose e piodermite, controlados, respectivamente, com banhos de dimetilciclopropano carboxilato (Butox-P - Quimio S.A.) diluído em solução aquosa na proporção de $1 / 6.000 \mathrm{ml}$ e higiene local das feridas, com gaze embebida em solução fisiológica. A medida da ingestão alimentar, obtida por meio da subtração entre a pesagem do alimento oferecido e o alimento restante na gaiola, ao final de 12 horas, foi maior no Grupo Diabético com diferenças estatisticamente significativas entre os 2 grupos $(\mathrm{P}<$ $0,05)$. Da mesma forma, a ingestão hídrica e a diurese de animais diabéticos apresentaram valores significativamente elevados, quando comparadas com ratos normais de mesma idade. Os gráficos desse grupo encontram-se representados, juntamente com o grupo controle normal (G1).

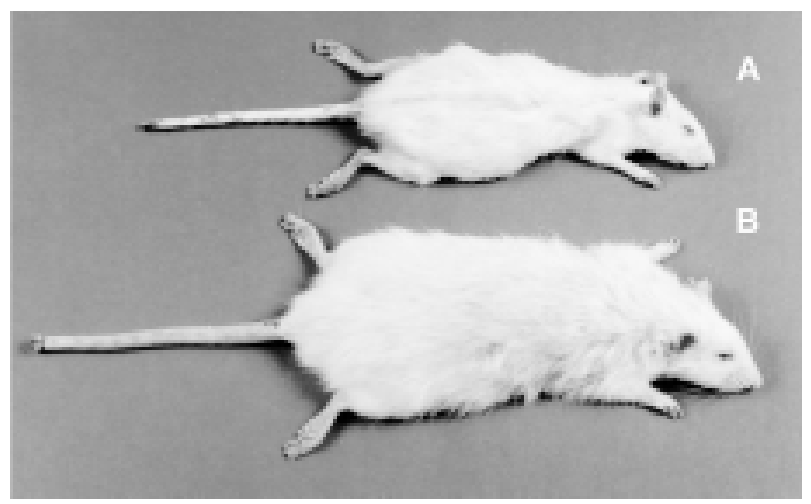

FIGURA 2 - Ratos com três meses de seguimento. Note a debilidade e a caquexia de um animal diabético (A), quando comparado à vitalidade de um animal normal de mesma idade (B). 

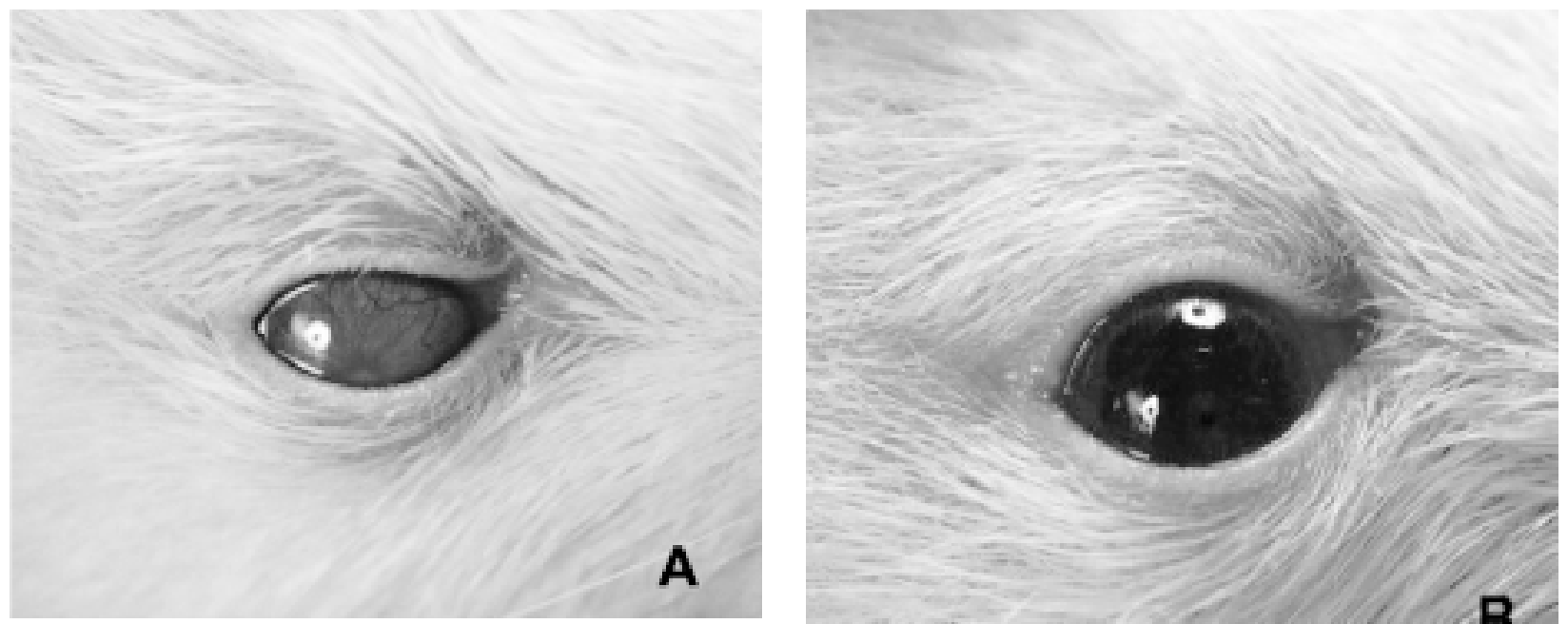

FIGURA 3 - Ratos com três meses de seguimento. Detalhe do olho de um animal diabético com catarata (A) e de um animal normal sem lesão (B).

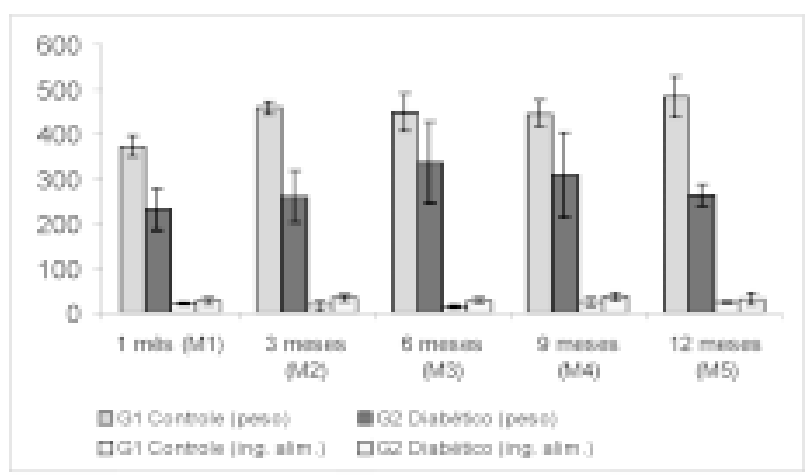

FIGURA 4 - Médias e desvio padrão do peso e ingestão alimentar, em gramas/12h, nos dois grupos experimentais, nos cinco momentos de avaliação.

\section{Evolução laboratorial}

Os dados relativos à dosagem da glicemia de jejum, da glicose urinária, colesterol total, colesterol HDL, triglicérides e lipídio total dos 25 animais acompanhados no Grupo Controle Normal (G1) durante o período de um ano, nos cinco momentos de avaliação, constam nas Figuras 6, 7 e 8. A análise da presença de glicose e corpos cetônicos na urina, através de fitas reagentes, revelou-se negativa em todos os animais, durante todo o experimento.

Todos os 25 animais acompanhados no Grupo Diabético (G2) apresentaram alterações laboratoriais representadas por glicemia de jejum acima de 300 $\mathrm{mg} / \mathrm{dl}$ e glicose urinária superior ou igual a 3.000 $\mathrm{mg} / \mathrm{dl}$, glicosúria $(+++)$ e, eventualmente, cetonúria. Esses parâmetros foram compatíveis com o estado diabético grave. Entre as alterações apresentadas, ao longo dos cinco momentos de avaliação, observou-se diferenças estatisticamente significativas quando

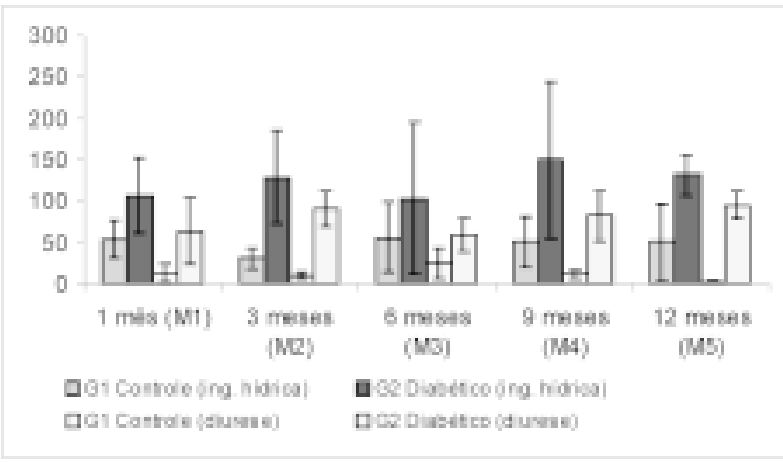

FIGURA 5 - Médias e desvio padrão da ingestão hídrica e diurese, em $\mathrm{ml} / 24 \mathrm{~h}$, nos dois grupos experimentais, nos cinco momentos de avaliação.

comparadas com o Grupo Controle Normal (G1). Os dados referentes a esses achados, com suas ilustrações, encontram-se nas figuras já mencionadas, juntamente com os dados do grupo controle normal $(\mathrm{Gl})$.

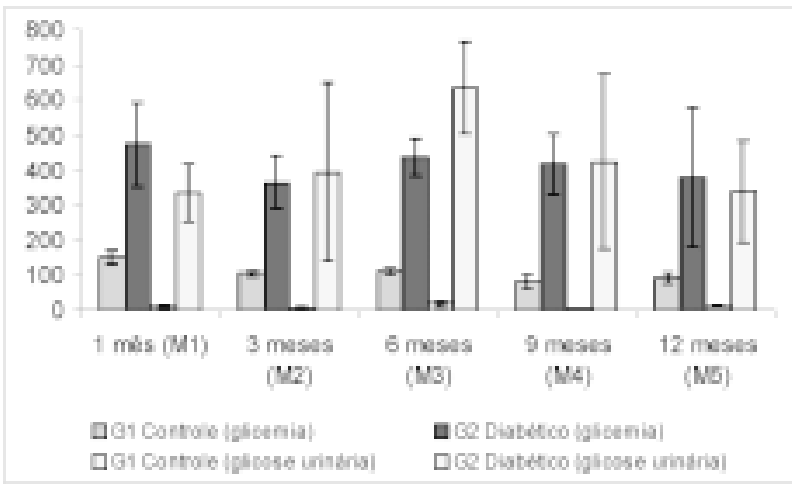

FIGURA 6 - Médias e desvio padrão da glicemia de jejum, em $\mathrm{mg} / \mathrm{dl}$ e da glicose urinária em $\mathrm{mg} / \mathrm{dl} \times 10^{-1}$, nos dois grupos experimentais, nos cinco momentos de avaliação. 


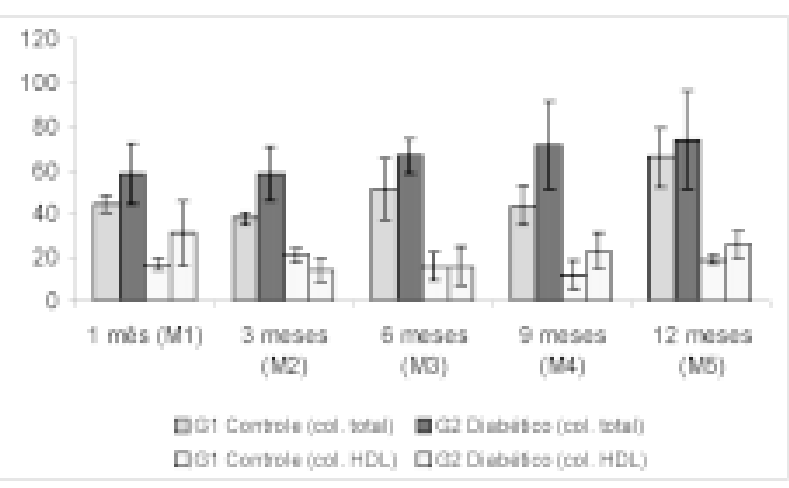

FIGURA 7 - Médias e desvio padrão do colesterol total e fração $\mathrm{HDL}$, em $\mathrm{mg} / \mathrm{dl}$, nos dois grupos experimentais, nos cinco momentos de avaliação.

\section{Discussão}

No presente estudo utilizamos ratos (Rattus novergicus) como animais de experimentação, por apresentarem inúmeras vantagens em relação ao cão e a outros animais de maior porte: a) fácil manuseio (alimentação, higiene, acomodação); b) possibilidade de trabalhar simultaneamente com vários grupos experimentais, sem a ocupação de grandes espaços; c) elevada resistência à infecção; d) facilidade para remoção dos diversos órgãos estudados (retina, rins, coração, aorta e ilíacas); e) redução de gastos com o projeto. Além desses fatos, por apresentarem semelhanças clínicas, laboratoriais e histopatológicas com o diabetes humano, os modelos experimentais de diabetes induzidos no rato têm sido amplamente utilizados por pesquisadores em todo o mundo (Junod e col. ${ }^{6}$; Orloff e col. ${ }^{7}$; Spadella ${ }^{8}$; Schellini ${ }^{9}$ ).

Como o diabetes é um doença crônica, cujas manifestações patológicas sobre os rins, retina e vasos estão nitidamente relacionadas ao tempo de exposição do hospedeiro às anormalidades metabólicas causadas pela doença, optou-se pelo seguimento a longo prazo dos animais, nos dois grupos experimentais, por 12 meses; tempo esse demonstrado como suficientemente capaz de produzir as alterações orgânicas de interesse ao nosso estudo.

Neste trabalho experimental utiliza-se a aloxana como droga diabetogênica. Porém, o diabetes experimental pode ser induzido em animais, por vários mecanismos. Infelizmente, porém, em grande número de métodos, o agente utilizado não é capaz de desenvolver a maior parte da fisiopatologia do diabetes humano. Os principais mecanismos de produção de diabetes são: estresse, infecções, toxinas, ou manipulações, incluindo a pancreatectomia; lesões do sistema nervoso central; uso de hormônios antiinsulínicos; exposição à hidrocortisona ou $\mathrm{ACTH}$;

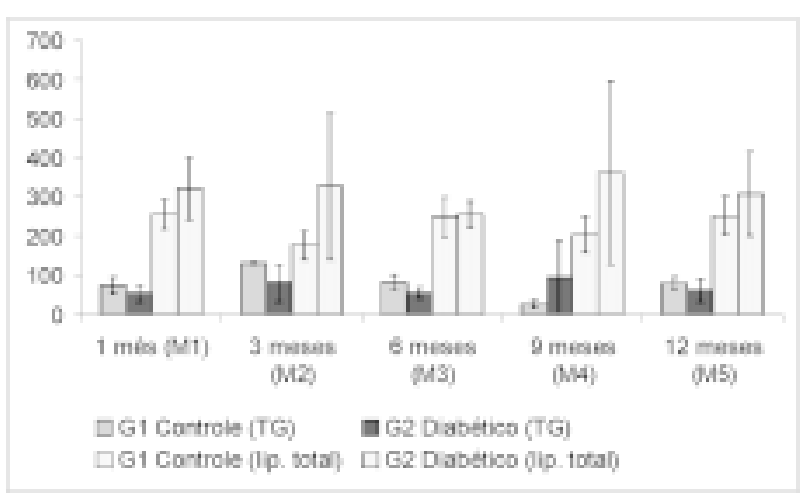

FIGURA 8 - Médias e desvio padrão do triglicérides (TG) e lipídio total, em mg/dl, nos dois grupos experimentais, nos cinco momentos de avaliação.

indução por vírus e o uso de agentes químicos betacitotóxicos.

A pancreatectomia total consiste em método clássico de obtenção de diabetes experimental. A ressecção parcial do pâncreas também produz diabetes, cujos aspectos clínico-laboratoriais se assemelham ao diabetes quimicamente induzido pela aloxana. A utilização desses métodos de ressecção, entretanto, tem sido restrita principalmente a animais de maior porte, além de incorrer necessariamente num procedimento cirúrgico adicional, com todas as suas implicações.

As lesões hipotalâmicas podem causar obesidade em animais e humanos, acompanhada de Diabetes Melittus proporcional ao ganho de peso. Ratos adultos, sujeitos a lesões do núcleo ventrículo-medial do hipotálamo, tornam-se obesos, hiperglicêmicos, hipoinsulinêmicos e insulino-resistentes; estudos desta natureza, contudo, além de terem uma fisiopatologia diversa do diabetes insulino-dependente, certamente implicariam em maior complexidade de execução e o conhecimento aprofundado de neurofisiologia, o que fugiria completamente aos nossos objetivos.

A utilização de hormônios com efeitos antagônicos à insulina, incluindo a epinefrina, o glucagon, os glicocorticóides e o hormônio de crescimento, ainda que capazes de produzir hiperglicemia, como na resposta fisiológica ao estresse, ou em certas condições patológicas (tumores, distúrbios metabólicos), tem seus efeitos discutíveis em animais, exercendo, principalmente no caso da epinefrina e do glucagon, um efeito antiinsulínico, somente se administrados em altas doses.

Vários estudos têm reportado a indução de hiperglicemia e hiperplasia das células beta em camundongos (Hausberger e Ramsay ${ }^{10}$ ), ratos (Cavellero e Mosca ${ }^{11}$ ), coelhos (Abelove e Paschiks ${ }^{12)}$, cobaios (Kerns e Logothetopoulos ${ }^{13}$ ) e macacos (Like e $\mathrm{Chick}^{14}$ ) por meio da exposição à hidrocortisona e 
ACTH. Os eventos bioquímicos, hormonais e morfológicos do diabetes, assim induzido, são, contudo, muito variáveis, o que comprometeria nossa avaliação.

A utilização de modelos virais para o diabetes experimental, relacionados aos vírus RNA, altamente espécie-específicos, além de se constituírem em risco potencial para o experimentador, tem ainda papel incerto na patogênese da doença.

Sendo assim, optamos por métodos químicos de supressão endócrina do pâncreas, os quais exibem todos os eventos bioquímicos, hormonais e morfológicos que ocorrem durante e após a indução do estado diabetogênico.

A aloxana e a estreptozotocina são os dois agentes químicos, com citotoxicidade específica para as células beta, mais estudados. Essas drogas causam insuficiência insulínica primária do pâncreas, provocando uma resposta trifásica nos níveis glicêmicos durante as primeiras horas da administração, seguida do estabelecimento de diabetes permanente nas 24 horas subseqüentes.

Esses métodos químicos, apesar de terem um elevado índice de mortalidade relativa, são de fácil execução e permitem a utilização de um grande número de animais, destruindo a parte endócrina do pâncreas, com preservação de sua função exócrina, tendo, ainda, a vantagem de estarem padronizados em nosso laboratório experimental.

Utilizamos a aloxana por via endovenosa, cuja atividade diabetogênica foi inicialmente notada por Dunn e col. (1943), quando estudava os efeitos do ácido úrico e seus derivados na produção da lesão renal em coelhos.

Essa opção permaneceu, apesar da maior especificidade da estreptozotocina sobre as células beta, com sua ação vinculada à dose de administração e com menor toxicidade geral que a aloxana, a qual exibe estreita margem de segurança entre as doses diabetogênicas e letais (Junod e col. ${ }^{6}$ ).

Duas razões nos levaram a essa escolha: a primeira, de ordem econômica, dado o alto custo da estreptozotocina, quando comparado com o da aloxana, cujos estoques estavam mais disponíveis em nosso laboratório experimental; a segunda, pelo uso amplamente difundido da Aloxana na produção de diabetes experimental por inúmeros serviços de larga experiência no assunto (Orloff e col. ${ }^{\mathrm{a} 16, \mathrm{~b} 17, \mathrm{cl} 18}$ ), incluindo a nossa unidade (Macedo e col. ${ }^{19}$; Calderon ${ }^{20}$; Spadella ${ }^{8}$; Breim ${ }^{21}$; Schellini ${ }^{9}$; Machado ${ }^{22}$ ).

A aloxana administrada por via endovenosa, na dose de $42 \mathrm{mg} / \mathrm{kg}$ de peso corporal, produziu em nossos animais diabetes franco, com o desenvolvimento de alterações clínicas e laboratoriais, bem definidas, incluindo, respectivamente, elevação da ingestão hídrica e da diurese, valores glicêmicos acima de $300 \mathrm{mg} / \mathrm{dl} \mathrm{e}$ glicose urinária maior que $3000 \mathrm{mg} / \mathrm{dl}$.

Em nosso estudo, dos 64 animais submetidos à injeção endovenosa de aloxana, 14 ratos $(21,8 \%)$ não ficaram diabéticos ou apresentaram diabetes de gravidade leve ou moderada, sendo desprezados. Dos 50 animais restantes, 25 ratos (39\%) morreram durante a primeira semana após a indução, tendo a mortalidade maior ocorrido nas primeiras 72 horas do experimento, e, finalmente, 25 ratos (39\%) desenvolveram diabetes grave, tendo sido colocados em seguimento.

Esses resultados são, em parte, discordantes dos relatados por Calderon (1988), cujos estudos em ratas não tratadas com diabetes aloxânico demonstraram uma porcentagem de $50 \%$ de animais diabéticos, $32,5 \%$ de animais normais e um índice de mortalidade de $17,5 \%$, até o $15^{\circ}$ dia após a indução. Este índice diabetogênico aparentemente elevado (50\%) explica-se, no entanto, em razão dos critérios de classificação do diabetes utilizado pela autora, a qual considerou diabéticos animais com glicemia superior ou igual a $120 \mathrm{mg} / \mathrm{dl}$. Se considerarmos apenas os ratos cujos valores glicêmicos foram superiores a $200 \mathrm{mg} / \mathrm{dl}$, sendo essa a sistemática por nós utilizada, observamos que o seu percentual de ratos diabéticos graves foi de $37,5 \%$, valores muito próximos aos por nós obtidos.

Em relação à taxa de mortalidade, obtivemos, em nossa pesquisa, um índice da ordem de 39\%. Lukens ${ }^{23}$, em extensa revisão da literatura a respeito da ação da aloxana sobre animais de várias espécies, incluindo o rato, o cão, o coelho, o macaco, o gato, mostrou índices muito variáveis de mortalidade, oscilando entre $33 \%$ e $100 \%$, na mesma espécie. Essas cifras amplas estão ligadas a múltiplos fatores capazes de mudar os efeitos da droga e a sensibilidade do hospedeiro, envolvendo desde o estado de hidratação da droga, a velocidade de infusão, a via de administração, a dieta, o tempo de jejum, o peso do animal e até a utilização de substâncias capazes de influenciar os seus mecanismos de ação, tais como os barbitúricos, o ácido nicotínico, o 1-2-dimetil-4 amino-5-benzeno, etc.). Os ratos, por exemplo, são mais sensíveis a uma dose constante de aloxana, após terem sido alimentados previamente com uma dieta de alto teor de gorduras. As taxas de mortalidade, nesses casos, alcançam $90 \%$ a $100 \%$. Por outro lado, dietas pobres em gordura, com altas concentrações de proteínas e carboidratos, são capazes de diminuir esses índices para 33\% a 40\%.

O jejum também tem um papel importante na resposta das espécies à aloxana. Noventa e cinco por 
cento dos ratos tratados com aloxana, administrada com o animal em jejum prolongado de 48 a 60 horas, tornamse diabéticos. A administração de uma dose similar de aloxana, quando o jejum não foi observado, diminui essa resposta para $25 \%$.

Lukens $^{23}$, revisando os trabalhos de vários autores, cita que animais que não respondem a uma primeira injeção de aloxana podem ser refratários a injeções posteriores de doses similares. Nesse aspecto, os autores têm observado que os animais que apresentam este comportamento geralmente são do grupo em que o jejum não foi convenientemente observado. Esses mesmos animais, refratários às doses subseqüentes, tornam-se diabéticos após 60 horas de jejum, com uma dose padrão de aloxana.

Outro aspecto a considerar são as vias de administração da droga. A via endovenosa tem sido a de escolha na maioria das espécies animais, onde os efeitos da aloxana são mais evidentes. As vias subcutânea e intraperitoneal também são satisfatórias no rato, enquanto que, no coelho, doses muito elevadas devem ser ministradas por essas vias, para que se atinja o mesmo efeito diabetogênico. Finalmente, a via oral é usualmente insatisfatória para a ação da aloxana, muito embora o diabetes possa ser produzido em ratos, coelhos e gatos, se a droga for rapidamente ingerida com comida, após um jejum prévio prolongado ${ }^{23}$.

Quando a via endovenosa é usada, a velocidade de infusão da droga é importante. Doses efetivas de aloxana não produzem diabetes se as mesmas são injetadas muito lentamente.

Gitter e Prieto-Diaz (1946) revelaram, segundo Lukens ${ }^{23}$, a importância do peso, em relação a susceptibilidade do animal aos efeitos tóxicos da aloxana. Em um estudo detalhado em ratos, esses pesquisadores revelaram que a toxicidade da aloxana altera-se numa relação linear com o peso do animal, aumentando 0,73 poderes de toxicidade para cada unidade de peso. Essa fórmula foi utilizada para estabelecer a dose letal de aloxana para cada rato.

Finalmente, algumas substâncias agem direta ou indiretamente sobre os mecanismos de ação da aloxana. Os barbitúricos tornam os animais mais sensíveis aos efeitos da droga. Por outro lado, algumas substâncias, tais como o ácido nicotínico, o 1-2-dimetil-4 amino-5benzeno e o ácido dicarboxílico piridínico, podem proteger o animal desses danos, se administrados simultaneamente com a droga ${ }^{23}$.

Em relação à evolução clínica e laboratorial dos animais diabéticos, analisada neste estudo, observamos alterações características muito similares ao diabetes humano, que contrastaram completamente da evolução de animais sadios.
Enquanto no grupo controle normal (G1) os animais apresentaram-se, ao longo do experimento, em bom estado geral, ativos, com apetite normal, tônus e reflexos conservados e um ganho progressivo de peso e manutenção da ingestão hídrica, ingestão alimentar e diurese, dentro dos padrões de normalidade para a espécie e em conformidade com outros trabalhos (Brekke e col. ${ }^{24}$ ), o comportamento dos animais do grupo diabético $(\mathrm{G} 2)$ foi completamente diferente sendo caracterizado por apatia, alterações da pelagem, odor forte da urina, anorexia, alem de comprometimento acentuado e progressivo do estado geral,com polaciúria, polidipsia, polifagia e altos volumes de débito urinário. A polaciúria, uma das características do estado hiperglicêmico, ocorreu devido ao aumento elevado da concentração de glicose no filtrado glomerular, excedendo a capacidade das células tubulares em reabsorvêla e dando origem à diurese osmótica. Esse mecanismo tem sido o responsável pela produção de grande volume de urina com elevada osmolaridade.

A polidipsia presente nos animais diabéticos devese à hiper-osmolaridade sangüínea, em razão de altos níveis de glicose circulante, que faz a água passar do meio intracelular para o extracelular, a fim de manter o equilíbrio osmótico. A desidratação intracelular é percebida pelos osmorreceptores cerebrais, desencadeando sede intensa.

Essas alterações estiveram associadas, ainda, à debilidade geral, pouca atividade, queda de pêlos, distensão abdominal, catarata bilateral e episódios freqüentes de pediculose e piodermites. Esses quadros foram relatados por Lee e col. ${ }^{25}$; Ueda e col. ${ }^{26}$; Brekke e col. ${ }^{24}$; Calderon ${ }^{20}$; Spadella ${ }^{8}$ e Breim ${ }^{21}$, em estudos com o diabetes induzido por aloxana ou pela estreptozocina.

As dosagens de glicemia de jejum, glicose urinária e glicosúria observadas nos 25 animais do grupo controle normal (G1), também mostraram-se dentro dos limites da normalidade para a espécie, durante o seguimento. Por outro lado, os 25 animais do grupo diabético (G2) evoluíram com parâmetros laboratoriais compatíveis com diabetes grave, em níveis estatisticamente significativos, como observamos em trabalhos anteriores; (Ueda e col. ${ }^{26}$; Spadella ${ }^{8}$ ).

$\mathrm{O}$ estudo do perfil lipídico dos animais, baseado nas dosagens de colesterol total, triglicérides e lípides, mostrou resultados muito próximos entre o grupo controle normal (G1) e o grupo diabético (G2), havendo, inclusive, momentos nos quais o grupo Gl superou o grupo G2 ou igualou-se a ele, como observado nas dosagens médias de triglicérides e lípides. Em relação ao colesterol HDL, BARR et al. (1951) ${ }^{27}$ já mostravam 
haver relação inversa entre os valores do HDL e a doença aterosclerótica. Miller e Miller ${ }^{28}$, salientando o papel protetor do HDL. Lastória e $\mathrm{Maffe}^{29}$ referiram a hipercolesterolemia como importante fator de risco para a doença aterosclerótica. Em trabalhos experimentais com ratos Wistar, Balasubramaniam e col. $1990^{30}$, demonstraram a redução de $48 \%$ das concentrações séricas do colesterol total e de $72 \%$ dos triglicérides, após sete dias de utilização de ACAT (Cholesterol Acyl Transferase), incorporado à dieta dos animais.

Foram observados que os valores médios do colesterol HDL foram significativamente superiores no grupo diabético (G2) em relação ao grupo controle normal (G1). Tal fato poderia, eventualmente, conferir uma proteção ao desenvolvimento da doença aterosclerótica macrovascular em animais diabéticos, contrariamente ao que se observa em humanos. A gênese desses achados, no entanto, ainda não foi elucidada, exigindo novas investigações.

\section{Conclusão}

Baseados nos resultados obtidos e nas condições experimentais do presente trabalho, concluímos que:

A - A aloxana a $2 \%$, na dose de $42 \mathrm{mg} / \mathrm{kg}$ de peso corporal, induziu diabetes experimental grave no rato, demonstrado por alterações clínicas e laboratoriais bem caracterizadas;

B - Em contraste ao observado na espécie humana, os animais diabéticos não apresentam alterações do perfil lipídico, sendo este fato de grande importância na presença da macroangiopatia diabética experimental do rato.

\section{Referências}

1. Franco LJ, Milech A, Braga CDC, Malerbi D, Campos GP, Almeida L, Schmidt MI, Albuqyerque RH. Estudo multicêntrico sobre a prevalência do Diabetes Mellitus no Brasil. Ministério da Saúde. Censo de Diabetes 1998; 1-32.

2. La Porte RE. Cruickshanks: incidence and risk factors for insulin-dependent diabetes. In: Harris MI, Hamman RF. Diabetes in America. Washington: National Diabetes Data Group, Niaddk/US Dept Health and Human Services; 1985. p. 1-12.

3. Królewski AS, Warram JH, Rand LI, Kann CR. Epidemiologic approach to the etiology of type I diabetes mellitus and its complications. N Engl J Med 1987;317:1390-8.

4. Kuller WH. Epidemiology of cardiovascular diseases: current prospectives. Am J Cardiol 1976;38:46.

5. Montgomery DC. Design and analyses of experiments. New York: John Wiley; 1991.

6. Junod A, Lambert AE, Stauffacher W, Renold AE. Diabetogenic action of streptozotocin: relationship of dose to metabolic response. J Clin Invest 1969;48:2129-39.

7. Orloff MJ, Lee S, Charters AC, Grambort DE, Storck G, Knox D. Long-term studies of pancreas transplantation in experimental diabetes mellitus. Ann Surg 1975;182:198-206.
8. Spadella CT. Avaliação funcional do transplante pancreatoduodenal no rato diabético: estudo clínico, laboratorial, anátomo-patológico e imunohistoquímico [Tese - Doutorado]. Universidade Estadual Paulista - Faculdade de Medicina de Botucatu; 1989.

9. Schellini SA. Retinopatia diabética experimental: estudo estrutural, ultraestrutural e morfométrico da retina de ratos normais, diabéticos e diabéticos tratados. [Tese - Doutorado] Universidade Estadual Paulista - Faculdade de Medicina de Botucatu; 1992.

10. Hausberger FX, Ramsay AJ. Islet hipertrophy in obesity of mice bearing ACTH-secreting tumors. Endocrinology $1959 ; 65: 165-9$

11. Cavellero C, Mosca L. Mitotic activity in the pancreatic islets of the rat under pituitary growth hormone and adrenocorticotropic hormone treatment. J Pathol Bacteriol 1953;66:147-51

12. Abelove WA, Paschiks KE. Comparison of the diabetogenic action of cortisone and growth hormone in different species. Endocrinology 1954;55:637-40.

13. Kern H, Logothetopoulos J. Steroid diabetes in the guinea pig: studies on islet cell ultrastructure and regeneration. Diabetes 1970;19:145-51

14. Like AA, Chick WL. Pancreatic betta cell replication induced by glucocorticoids in subhuman primates. Am J Pathol 1974;75:329-32

15. Dunn JS, Sheehan HL, McLetchie NGB. Necrosis of islets of Langerhans produced experimentally. Lancet 1943;1:484-7.

16. Orloff MJ, Macedo AR, Greenleaf GE. Effect of pancreas transplantation on diabetic somatic neuropathy. Surgery 1988a; $104: 437-44$.

17. Orloff MJ, Macedo AR, Greenleaf GE, Girard B Comparison of the metabolic control of diabetes achieved by whole pancreas transplantation and pancreatic islet transplantation in rats. Transplantation 1988b;45:307-12

18. Orloff MJ, Macedo AR, Macedo CS, Yamanaka N, Huang YT, Huang DG, Leng XS, Stieber A, Kreidieh I, Greenleaf GE Prevention, stabilization and reversal of the metabolic disorders and secondary complications of diabetes by pancreas transplantation. Transplant Proc 1988;20: 868-73.

19. Macedo CS, Riyuzo MK, Mercadante MCS, Capeletti SM, Hernandes D, Spadella CT, Breim LC, Roso SLO, Padovani CR, Macedo AR. Nefropatia diabética em ratos: estudo comparativo entre a diabetes induzida pela aloxana e pela estreptozotocina. In Anais da Jornada Brasileira de Nefrologia Pediátrica; 1987; Rio de Janeiro: Sociedade Brasileira de Pediatria, 1987. v. 41

20. Calderon IMP. Modelo experimental em ratas para estudo do binômio diabete e gravidez [Dissertação - Mestrado]. Universidade Estadual Paulista - Faculdade de Medicina de Botucatu; 1988.

21. Breim LC. Estudo comparativo entre o transplante total de pâncreas, transplante de ilhotas de Langerhans, e o tratamento convencional com insulina no controle das manifestações clínicas do diabetes aloxânico no rato [Dissertação - Mestrado] Universidade Estadual Paulista - Faculdade de Medicina de Botucatu; 1990.

22. Machado JLM. Neuropatia diabética experimental: estudo morfológico e morfométrico do nervo ciático de ratos diabéticos. [Dissertação - Mestrado]. Universidade Estadual Paulista - Faculdade de Medicina de Botucatu; 1993.

23. Lukens FDW. Alloxan diabetes. Physiol Rev 1948; 28:304-30.

24. Brekke IB, Hostmark AT, Flaten O, Oyasoeter S. Effect of pancreas transplantation on plasma lipids and plasma 
concentrations of pancreatic hormones in streptozotocin diabetic rats. Eur Surg Res 1981;13:361-70.

25. Lee S, Tung KSK, Koopmans H, Chandler JG, Orloff MJ Pancreaticoduodenal transplantation in the rat. Transplantation 1972;13:421-5.

26. Ueda T, Lee S, Storck G. Metabolic effect of Alloxan diabetic rats before and after pancreas transplantation. Proc Anat Microsurg Soc 1979;3:423-4.

27. Barr DP, Russ EM, Eder HA. Protein-lipid relationships in human plasma. Am J Med 1951;11:480-93.
28. Miller GK, Mioller ME. Plasma high density lipoprotein concentration and development os ischaemic heart disease. Lancet $1975 ; 1: 16$

29. Lastória S, Maffei FHA. Aterosclerose obliterante periférica (AOP): etiopatogenia, fisiopatologia, patologia e diagnóstico. In: Maffei FHA. Doenças vasculares periféricas. 2ed. São Paulo: MEDSI; 1995. p.419-39.

30. Balasubramaniam S. On the mechanism by which an ACAT inhibitor (CL277,082) influences plasma lipoproteins in the rat. Atherosclerosis 1990; 82:1-5.

Lerco MM, Spadella CT, Machado JLM, Schellini SA, Padovani CR. Experimental alloxan diabetesinduced: a model for clinical and laboratory studies in rats. Acta Cir Bras [serial online] 2003 MarApr;18(2). Available from URL: http://www.scielo.br/acb.

ABSTRACT - Purpose: This work aimed to determine the clinical and laboratory alterations of rat with Diabetes mellitus using alloxan endovenously. Methods: The animals were randomly assigned to two experimental groups: Normal Control Group (G1) with 25 healty animals and Diabetic Group (G2) with 25 severe diabetic animals. They were evaluated in 5 moments (1, 3, 6, 9 and 12 months) during which the following parameters were studied: clinical evolution (body weight, water intake, food intake, and diuresis) and biochemical exams (fast glycemia, urinary glucose, glucosuria, ketonury, total cholesterol, HDL cholesterol, triglycerides and lipids). Results: Alloxan $2 \%$ injection intravenously in the rat was followed by $39 \%$ death rate and also caused severe diabetes in $39 \%$ of the animals. Diabetes was characterized by progressive body weight loss, significative water intake, food intake and diuresis with blood glucose levels above $300 \mathrm{mg} / \mathrm{dl}$, glucosuria 3+ and eventually ketonury. Diabetes doesn't change profile a long-term of cholesterol and lipids levels. Conclusion: Our studies showed that alloxan causes clinical and laboratory alterations in the rat, what is typical of severe diabetes. They allow the long-term studies of diabetic.

KEY WORDS - Diabetes. Alloxan. Rat.

Conflito de interesse: nenhum

Fonte de financiamento: FAPESP

\section{Correspondência:}

Mauro Masson Lerco

Depto. Cirurgia e Ortopedia da Faculdade de Medicina de Botucatu - Unesp

18618-970 Botucatu - SP

m.masson@fmb.unesp.br

Data do recebimento: 19/01/2003

Data da revisão: 29/01/2003

Data da aprovação: 06/02/2003 